\title{
Antibiotic susceptibility pattern of organisms causing surgical site infection
}

\author{
Saranya K. Lakshmi ${ }^{1}$, Hema Narasimhe Gowda ${ }^{1 *}$, Anuradha K. ${ }^{2}$
}

${ }^{1}$ Department of Pharmacology, ${ }^{2}$ Department of Microbiology, Mysore Medical College and Research Institute, Mysore, Karnataka, India

Received: 06 July 2020

Accepted: 06 August 2020

*Correspondence:

Dr. Hema Narasimhe Gowda,

Email: dr.hema_ng@yahoo.com

Copyright: (C) the author(s), publisher and licensee Medip Academy. This is an open-access article distributed under the terms of the Creative Commons Attribution Non-Commercial License, which permits unrestricted non-commercial use, distribution, and reproduction in any medium, provided the original work is properly cited.

\begin{abstract}
Background: Approximately 30-50\% of antibiotic use in hospitals is now for pre-surgical prophylaxis. Selection of antibiotics for prophylaxis should be based on its activity against expected bacteria at the desired surgical site. Appropriate antibiotic prophylaxis can reduce the risk of postoperative morbidity and mortality. Abuse of antimicrobials increases the cost of treatment and supports the emergence of resistant bacteria. This study was undertaken with the primary objective of to test the antibiotic susceptibility pattern of organisms causing SSIs.

Methods: A descriptive study was carried out in general surgical wards of KR hospital, Mysore for a period of 18 months (2015-2016). The relevant data was collected from the case sheets of patients who were diagnosed with SSI. Pus samples were collected, and culture-sensitivity was done. Collected data were analysed using appropriate statistical tests.

Results: A total of 263 study subjects including both males and females were enrolled in the study. Out of 263 pus samples $92 \%$ were culture positive. The most common organisms causing SSI were E. Coli-ESBL (n=73) and MRSA $(n=44)$. Gram-negative organisms were highly resistant to $\beta$-lactam antibiotics and Gram-positive organisms were resistant to cotrimoxazole, erythromycin, clindamycin, cefoxitin and ciprofloxacin.

Conclusions: Good hygienic measures should be followed by the patients and health-workers. A revision of hospital antibiotic policy according to the local antibiotic susceptibility pattern is recommended.
\end{abstract}

Keywords: Antibiogram, Antibiotic resistance, Iatrogenic infection, Wound swab

\section{INTRODUCTION}

The introduction of routine surgical antimicrobial prophylaxis (SAP) was a breakthrough in the prevention of surgical site infections (SSIs). ${ }^{1}$ The extremely high efficacy of antimicrobial agents has proved to be a boon and curse. The double-edged sword has now many more edges; the sharpest is the development of resistance to antimicrobial agents. ${ }^{2}$ Antibiotic therapy eradicates not only pathogenic organisms but also the protective normal flora. ${ }^{3}$ As resistance towards antibiotics becomes more common a greater need for alternative treatments arises. However, despite a push for new antibiotic therapies there has been a continued decline in the number of newly approved drugs. Antibiotic resistance therefore poses a significant problem. ${ }^{4}$

Therefore, the prophylactic regimen in patients undergoing surgery should include an agent effective against the most likely infecting organisms but need not eradicate every potential pathogen. The choice of antibiotic should be based on the local antibiogram. ${ }^{5}$ Antibiogram provides qualitative results by categorizing bacteria as susceptible, intermediate or resistant. Ultimately, the results will guide the clinicians in the appropriate selection of initial empiric treatments and 
antibiotics used for individual patients' situations. $^{6}$ Several studies on SSI have witnessed the presence of organisms which are resistant to a range of antibiotics as follows. A study done by Akhi et al says that the most common organisms causing SSI are Enterobacteriaceae spp. (sensitive to Imepenem), Pseudomonas aeruginosa and Staphylococcus aureus (sensitive to vancomycin and linezolid) in descending order. ${ }^{7}$ A short report by Hubab et al shows that the E. Coli and S. aureus are the two most common organisms associated with causing SSI and linezolid, vancomycin, cefoperazone and meropenem are the most effective antibiotics in treating those. ${ }^{8}$

Hence, the present study is undertaken in surgical wards to look for the antibiotic susceptibility of isolates from surgical site infection which could educate the treating clinicians to help them improve their quality of treatment.

\section{METHODS}

This prospective study was undertaken in surgical wards for a period of 18 months ( $1^{\text {st }}$ January 2015-30 ${ }^{\text {th }}$ June 2016) to study the proportion of surgical site infections, to look for the pattern of antibiotic usage, to test the antibiotic susceptibility of isolates from SSI and to observe any change in antibiotic usage in case of development of resistance.

Prior to data collection the study protocol with written informed consent form was submitted; and the study was approved by the Institutional Ethics Committee.

The study population included those who were diagnosed with SSI and admitted in the general surgery ward. The type of sampling was the purposive sampling. Using estimation technique with prevalence of SSIs $22 \%$, margin of error at $5 \%$ and level of significance $5 \%$, the sample size was found to be 263 . The inclusion criteria were the patients older than 18 years of either sex; who had undergone abdominal surgeries and diagnosed with SSI. After obtaining written informed consent, following data were collected;

Socio-demographic details like name, age, sex, address, height and weight; history of any co-morbidities like diabetes mellitus; history of taking any drugs (hypoglycemic drugs, hypolipidemic drugs and corticosteroids); history of recent surgeries, prior irradiation, recent hospitalization, antibiotic usage; diagnosis and the surgery done; the antibiotics used as pre-surgical prophylaxis and pre-op skin preparation; intra-op history of blood transfusion, type of surgery; the wound details (soakage of wound dressing, pain, swelling, pus collection and history of fever); the details of post op antibiotics given were noted down in the preformed performa from the medical records of respective study subject; additionally, the date of pus sample collection and the date of collecting the culture report were also noted.

\section{Collection and processing of pus sample}

Using sterile cotton swab the pus or discharge from the surgical wound was collected after cleaning the wound with saline swab. The pus sample was immediately transferred to Microbiology laboratory for further processing. All the samples were processed as per standard guidelines. Smear was prepared and stained by gram's stain. Specimen was inoculated onto Mac Conkey and blood agar. Isolates were identified by standard protocol.

\section{Antibiotic susceptibility testing}

Susceptibility testing was performed by Kirby-Bauer disk diffusion technique according to criteria set by Clinical and Laboratory Standards Institute (CLSI) 2011. The inoculum was prepared by picking parts of similar test organisms with a sterile wire loop and suspended in sterile normal saline. The density of suspension to be inoculated was determined by comparison with opacity standard on McFarland 0.5 Barium sulphate solution.

The test organism was uniformly seeded over the Mueller-Hinton agar and exposed to a concentration gradient of antibiotic diffusing from antibioticimpregnated paper disk into the agar medium, and then incubated at $37^{\circ} \mathrm{C}$ for $16-18$ hours. Diameters of the zone of inhibition around the discs were measured to the nearest millimetre using a ruler and classified as sensitive, intermediate, and resistant according to the standardized table supplied by CLSI 2011. ${ }^{9}$ The discs were selected based on gram positive and gram-negative organisms.

The discs used for gram positive organisms were penicillin $\mathrm{G}$ (10 units); amoxicillin $(10 \mu \mathrm{g})$; cefoxitin (30 $\mu \mathrm{g})$; erythromycin (15 $\mu \mathrm{g})$; clindamycin (2 $\mu \mathrm{g})$; gentamycin $(10 \mu \mathrm{g})$; ciprofloxacin $(5 \mu \mathrm{g})$; cotrimoxazole $(25 \mu \mathrm{g})$; vancomycin $(30 \mu \mathrm{g})$; teicoplanin $(15 \mu \mathrm{g})$ and aztreonam $(30 \mu \mathrm{g})$. The discs used for gram negative bacteria amoxicillin-clavulanate $(30(20 / 10) \mu \mathrm{g})$, cefalexin $(30 \mu \mathrm{g})$; cefaclor $(30 \mu \mathrm{g})$; ceftriaxone $(30 \mu \mathrm{g})$; cefotaxime $(30 \mu \mathrm{g}) ;$ cefotaxime + clavulanate $(30 / 10 \mu \mathrm{g})$; cefoperazone $(75 \mu \mathrm{g})$; cefepime $(30 \mu \mathrm{g})$; gentamycin $(10$ $\mu \mathrm{g})$; ciprofloxacin $(5 \mu \mathrm{g})$; cotrimoxazole $(25 \mu \mathrm{g})$; colistin $(10 \mu \mathrm{g})$; piperacillin + tazobactum $(100 / 10 \mu \mathrm{g})$; imipenem $(10 \mu \mathrm{g})$; Tigecyclin $(15 \mu \mathrm{g})$ and aztreonam (30 $\mu g)$.

\section{Statistical analysis}

Statistical tests applied for data analysis were descriptive statistics, Chi square test and Cramer's V test. Statistical analysis was done using R-software.

\section{RESULTS}

A total of 263 patients who were admitted in the General surgery ward diagnosed with SSI were enrolled in the 
study. The most common age group was 41-60 years $(42.2 \%)$ and the most common gender was male $(58.17 \%)$. Out of 263 study subjects, around $14.4 \%$ were diagnosed with intestinal perforation, $12.5 \%$ with diabetic cellulitis (DM cellulitis) and $12.2 \%$ with acute appendicitis which were found to be the three most common diagnoses.

Surgical conditions like cholelithiasis (7.6\%), paraumbilical hernia (6.8\%), carcinoma breast $(6.1 \%)$, incisional hernia $(3.4 \%)$, umbilical hernia $(3 \%)$, breast abscess (2.7\%), fibro-adenoma breast $(2.3 \%)$ were encountered in the study and other conditions like carcinoma rectum, appendicular mass etc., contributed around $25 \%$. The data was found to be statistically significant ( $\mathrm{p}$ value <0.001) (Figure 1).

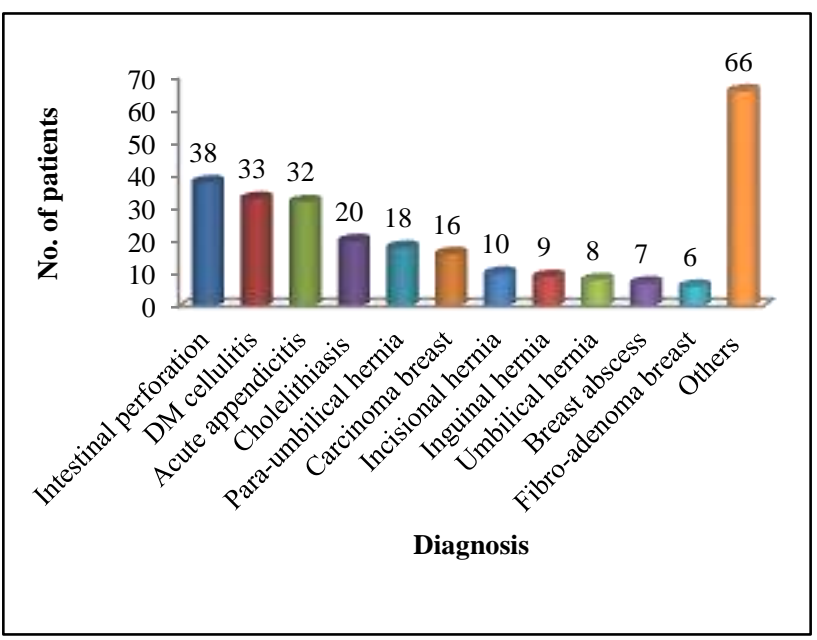

Figure 1: Surgical diagnoses.

Open APR (Open abdomino-perineal resection) (22.1\%), Mesh repair (18.6\%) and Open appendectomy (14.4\%) were the first three most common surgeries recorded in our study. Open APR was significantly higher than other surgeries done ( $\mathrm{p}$ value <0.001). Amputation (11\%), cholecystectomy $(9.1 \%)$, modified radical mastectomy $(14 \%)$, excision $(4.6 \%)$ etc., were the other surgeries included in our study (Figure 2).

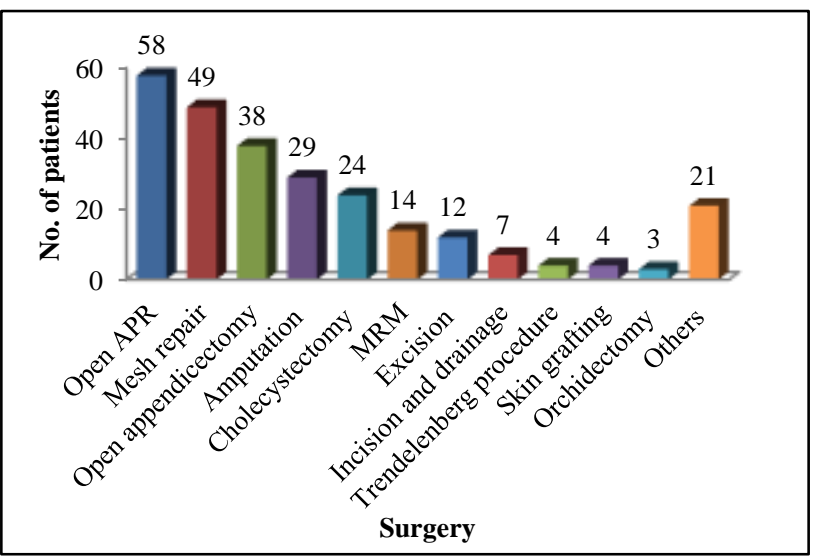

Figure 2: Surgeries done.
Out of 263, around 84 surgeries were belonging to clean contaminated category $(31.9 \%)$ which was significantly higher when compared to other surgical categories $(\mathrm{p}=0.001)$. The other three categories of surgery like clean $(n=79)$, dirty $(n=54)$ and contaminated surgeries $(n=46)$ contributed around $30 \%, 20.5 \%$ and $17.5 \%$ respectively (Figure 3).

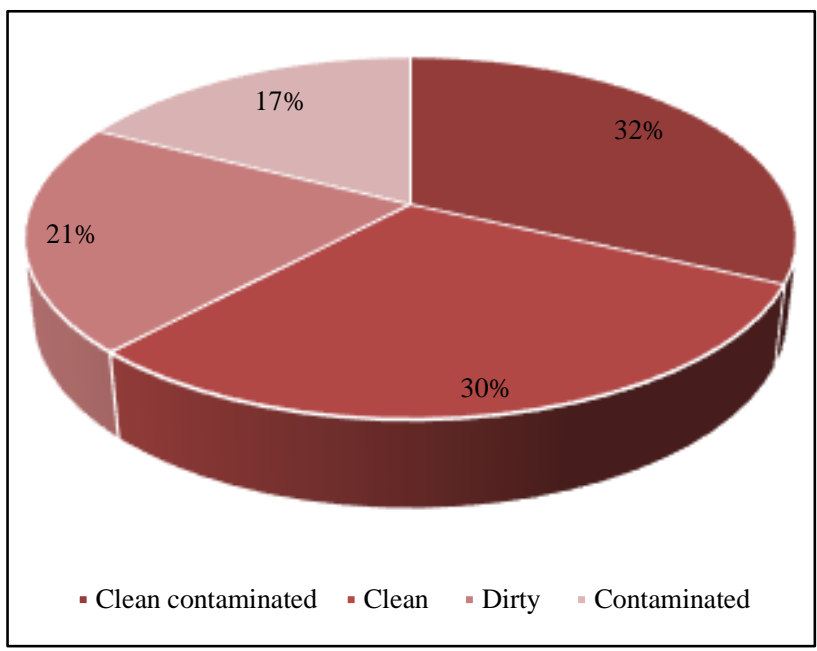

Figure 3: Surgical categories.

The most common organism causing SSI was E. ColiESBL (73 cases). The second most common are E. Coli and MRSA both contributed 44 cases of SSI each. No growth was seen in 22 study cases. Other organisms found in our study were Klebsiella (17), Pseudomonas aeruginosa (17), Proteus (13), Acinetobacer (10), Citrobacter (10), methicillin resistant coagulase negative staphylococcus aureus- MRCoNS (8), enterobacter (6) and Staphylococcus aureus (5) (Figure 4).

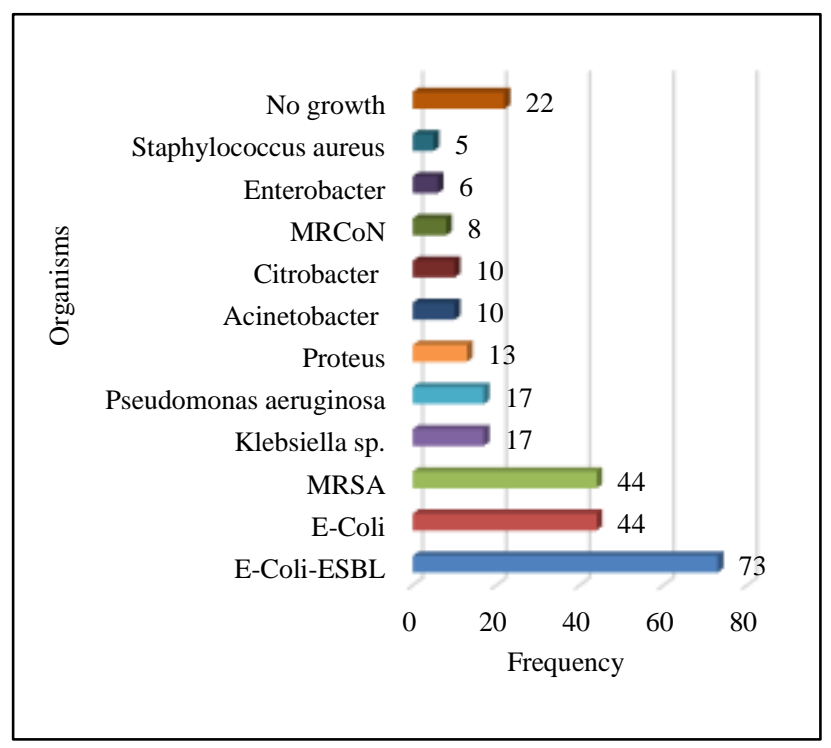

Figure 4: Pathogens causing SSIs.

MRSA and MRCoNs showed $100 \%$ resistance to penicillin. All the gram-positive cocci were $100 \%$ 
sensitive to vancomycin and linezolid. MRSA showed $>50 \%$ resistance towards cotrimoxazole, erythromycin, clindamycin, cefoxitin and ciprofloxacin. MRCoNs showed $\geq 50 \%$ resistance towards cefoxitin, cefaclor, erythromycin, ciprofloxacin and cotrimoxazole. Staphylococcus aureus was $>50 \%$ resistant against gentamycin, erythromycin, clindamycin, ciprofloxacin and cotrimoxazole (Table 1).

Table 1: Antibiotic susceptibility pattern of gram-positive organisms.

\begin{tabular}{|c|c|c|c|c|c|c|}
\hline \multirow{3}{*}{ Antibiotics tested } & \multicolumn{6}{|c|}{ Gram Positive Organisms, n (\%) } \\
\hline & \multicolumn{2}{|c|}{ MRSA (n=44) } & \multicolumn{2}{|c|}{$\operatorname{MRCoNS}(n=8)$} & \multicolumn{2}{|c|}{ Staphylococcus aureus $(\mathrm{n}=5)$} \\
\hline & $\mathbf{R}$ & $\mathbf{S}$ & $\mathbf{R}$ & $\mathbf{S}$ & $\mathbf{R}$ & $\mathbf{S}$ \\
\hline Penicillin & $44(100)$ & $0(0)$ & $8(100)$ & $0(0)$ & $0(0)$ & $5(100)$ \\
\hline Amoxicillin & NT & NT & NT & NT & $1(20)$ & $4(80)$ \\
\hline Amoxicillin + Clavulanate & NT & NT & NT & NT & $1(20)$ & $4(80)$ \\
\hline Cefoxitin & $25(56.8)$ & $19(43.2)$ & $6(75)$ & $2(25)$ & NT & NT \\
\hline Cefaclor & $20(45.5)$ & $24(54.5)$ & $6(75)$ & $2(25)$ & NT & NT \\
\hline Erythromycin & $29(65.9)$ & $15(34.1)$ & $6(75)$ & $2(75)$ & $3(60)$ & $2(40)$ \\
\hline Clindamycin & $25(56.8)$ & $19(43.2)$ & $3(37.5)$ & $5(62.5)$ & $3(60)$ & $2(40)$ \\
\hline Gentamycin & $21(47.7)$ & $23(52.3)$ & $3(37.5)$ & $5(62.5)$ & $4(80)$ & $1(20)$ \\
\hline Ciprofloxacin & $22(52.4)$ & $20(47.6)$ & $5(62.5)$ & $3(37.5)$ & $3(60)$ & $2(40)$ \\
\hline Cotrimoxazole & $33(75)$ & $11(25)$ & $4(50)$ & $4(50)$ & $3(60)$ & $2(40)$ \\
\hline Vancomycin & $0(0)$ & $44(100)$ & $0(0)$ & $8(100)$ & $0(0)$ & $5(100)$ \\
\hline Teicoplanin & $9(20.5)$ & $35(79.5)$ & $1(12.5)$ & $7(87.5)$ & $2(40)$ & $3(60)$ \\
\hline Linezolid & $0(0)$ & $44(100)$ & $0(0)$ & $8(100)$ & $0(0)$ & $5(100)$ \\
\hline
\end{tabular}

Where, MRSA- Methicillin Resistant Staphylococcus aureus, MRCoNS - Methicillin Resistant Coagulase Negative Staphylococcus aureus, NT- Not Tested, R-resistance, S- sensitive, n-number.

Table 2: Pattern of antibiotic susceptibility in gram negative organisms.

\begin{tabular}{|c|c|c|c|c|c|c|c|c|c|}
\hline \multirow{2}{*}{\multicolumn{2}{|c|}{$\begin{array}{l}\text { Antibiotics } \\
\text { tested }\end{array}$}} & \multicolumn{8}{|c|}{ Gram negative organisms, n (\%) } \\
\hline & & \multirow{2}{*}{$\begin{array}{l}\begin{array}{l}\text { E. Coli } \\
\text { ESBL } \\
(\mathbf{n}=73)\end{array} \\
1(1.4)\end{array}$} & \multirow{2}{*}{$\begin{array}{l}\begin{array}{c}\text { E. Coli } \\
(\mathrm{n}=44)\end{array} \\
1(2.3)\end{array}$} & \multirow{2}{*}{$\begin{array}{l}\begin{array}{l}\text { Klebsiella } \\
(\mathbf{n}=17)\end{array} \\
0(0)\end{array}$} & \multirow{2}{*}{ 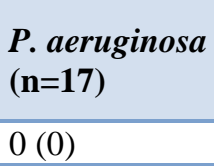 } & \multirow{2}{*}{$\begin{array}{l}\begin{array}{l}\text { Proteus } \\
(\mathbf{n}=13)\end{array} \\
0(0)\end{array}$} & \multirow{2}{*}{$\begin{array}{l}\begin{array}{l}\text { Acineto } \\
\text { bacter } \\
(\mathbf{n}=10)\end{array} \\
0(0)\end{array}$} & \multirow{2}{*}{$\begin{array}{l}\begin{array}{l}\text { Citrobacter } \\
(\mathbf{n}=\mathbf{1 0})\end{array} \\
0(0)\end{array}$} & \multirow{2}{*}{$\begin{array}{l}\begin{array}{l}\text { Enterobacter } \\
(\mathbf{n}=6)\end{array} \\
1(16.7)\end{array}$} \\
\hline $\mathbf{A M}$ & $\mathrm{S}$ & & & & & & & & \\
\hline $\mathbf{X}$ & $\mathrm{R}$ & $72(98.6)$ & $43(97.7)$ & $17(100)$ & $17(100)$ & $13(100)$ & $10(100)$ & $10(100)$ & $5(83.3)$ \\
\hline $\mathbf{A M}$ & $\mathrm{S}$ & $47(64.4)$ & $4(9.1)$ & $5(29.4)$ & $2(11.8)$ & $2(15.4)$ & $5(50)$ & $2(20)$ & $0(0)$ \\
\hline $\mathbf{C}$ & $\mathrm{R}$ & $26(35.6)$ & $40(90.9)$ & $12(70.6)$ & $15(88.2)$ & $11(84.6)$ & $5(50)$ & $8(80)$ & $6(100)$ \\
\hline \multirow{2}{*}{$\mathbf{C N}$} & $\mathrm{S}$ & $0(0)$ & $6(13.6)$ & $3(17.6)$ & $1(5.9)$ & $7(53.8)$ & $0(0)$ & $2(20)$ & $2(33.3)$ \\
\hline & $\mathrm{R}$ & $73(100)$ & $38(86.4)$ & $14(82.4)$ & $16(94.1)$ & $6(46.2)$ & $10(100)$ & $8(80)$ & $4(66.7)$ \\
\hline \multirow{2}{*}{ CTR } & $\mathrm{S}$ & $6(8.2)$ & $28(63.6)$ & $10(58.8)$ & $0(0)$ & $1(7.7)$ & $7(70)$ & $7(70)$ & $2(33.3)$ \\
\hline & $\mathrm{R}$ & $67(91.8)$ & $16(36.4)$ & $7(41.2)$ & $17(100)$ & $12(92.3)$ & $3(30)$ & $3(30)$ & $4(66.7)$ \\
\hline \multirow{2}{*}{ CTX } & $\mathrm{S}$ & $3(4.1)$ & $13(29.5)$ & $9(52.9)$ & $1(5.9)$ & $7(53.8)$ & $3(30)$ & $7(70)$ & $3(50)$ \\
\hline & $\mathrm{R}$ & $70(95.9)$ & $31(70.5)$ & $8(47.1)$ & $16(94.1)$ & $6(46.2)$ & $7(70)$ & $3(30)$ & $3(50)$ \\
\hline \multirow{2}{*}{ CEC } & $\mathrm{S}$ & 72 (98.6) & \multirow{2}{*}{ NT } & \multirow{2}{*}{ NT } & \multirow{2}{*}{ NT } & \multirow{2}{*}{ NT } & \multirow{2}{*}{ NT } & \multirow{2}{*}{ NT } & \multirow{2}{*}{ NT } \\
\hline & $\mathrm{R}$ & $1(1.4)$ & & & & & & & \\
\hline \multirow{2}{*}{ CAZ } & $\mathrm{S}$ & $1(1.4)$ & $29(65.9)$ & 3 (17.6) & $9(52.9)$ & $2(15.4)$ & $1(10)$ & $7(70)$ & $0(0)$ \\
\hline & $\mathrm{R}$ & 72 (98.6) & $15(34.1)$ & $14(82.4)$ & $8(47.1)$ & $11(84.6)$ & $9(90)$ & $3(30)$ & $6(100)$ \\
\hline \multirow{2}{*}{ CAC } & $\mathrm{S}$ & $73(100)$ & \multirow{2}{*}{ NT } & \multirow{2}{*}{ NT } & \multirow{2}{*}{ NT } & \multirow{2}{*}{ NT } & \multirow{2}{*}{ NT } & \multirow{2}{*}{ NT } & \multirow{2}{*}{ NT } \\
\hline & $\mathrm{R}$ & $0(0)$ & & & & & & & \\
\hline \multirow{2}{*}{ CPZ } & $\mathrm{S}$ & $1(1.4)$ & $24(54.5)$ & 3 (17.6) & $10(58.8)$ & $5(38.5)$ & $5(50)$ & $1(10)$ & $3(50)$ \\
\hline & $\mathrm{R}$ & $72(98.6)$ & $20(45.5)$ & $14(82.4)$ & $7(41.2)$ & $8(61.5)$ & $5(50)$ & $9(90)$ & $3(50)$ \\
\hline & $\mathrm{S}$ & $4(5.5)$ & $28(63.6)$ & $3(17.6)$ & $1(5.9)$ & $7(53.8)$ & $4(40)$ & $1(10)$ & $1(16.7)$ \\
\hline & $\mathrm{R}$ & $69(94.5)$ & $16(36.4)$ & $14(82.4)$ & $16(94.1)$ & $6(46.2)$ & $6(60)$ & $9(90)$ & $5(83.3)$ \\
\hline & $\mathrm{S}$ & $34(46.6)$ & $19(43.2)$ & $9(52.3)$ & $2(11.8)$ & $11(84.6)$ & $7(70)$ & $8(80)$ & $1(16.7)$ \\
\hline GEI & $\mathrm{R}$ & $39(53.4)$ & $25(56.8)$ & $8(47.1)$ & $15(88.2)$ & $2(15.4)$ & $3(30)$ & $2(20)$ & $5(83.3)$ \\
\hline & $\mathrm{S}$ & 27 (37) & $12(27.3)$ & $4(23.5)$ & $1(5.9)$ & $7(53.8)$ & $2(20)$ & $1(10)$ & $1(16.7)$ \\
\hline Cro & $\mathrm{R}$ & $46(63)$ & $32(72.7)$ & $13(76.5)$ & $16(94.1)$ & $6(46.2)$ & $8(80)$ & $9(90)$ & $5(83.3)$ \\
\hline
\end{tabular}




\begin{tabular}{|c|c|c|c|c|c|c|c|c|c|}
\hline \multirow{2}{*}{\multicolumn{2}{|c|}{$\begin{array}{l}\text { Antibiotics } \\
\text { tested }\end{array}$}} & \multicolumn{8}{|c|}{ Gram negative organisms, $\mathbf{n}$ (\%) } \\
\hline & & $\begin{array}{l}\text { E. Coli } \\
\text { ESBL } \\
(n=73)\end{array}$ & $\begin{array}{l}\text { E. Coli } \\
(n=44)\end{array}$ & $\begin{array}{l}\text { Klebsiella } \\
(n=17)\end{array}$ & $\begin{array}{l}P . \\
\text { aeruginosa } \\
(n=17)\end{array}$ & $\begin{array}{l}\text { Proteus } \\
(n=13)\end{array}$ & $\begin{array}{l}\text { Acineto } \\
\text { bacter } \\
(n=10)\end{array}$ & $\begin{array}{l}\text { Citrobacter } \\
(n=10)\end{array}$ & $\begin{array}{l}\text { Enterobacter } \\
(n=6)\end{array}$ \\
\hline \multirow{2}{*}{ COT } & $S$ & $35(47.9)$ & $9(20.5)$ & $9(52.9)$ & $2(11.8)$ & $7(53.8)$ & $5(50)$ & $2(20)$ & $3(50)$ \\
\hline & $\mathrm{R}$ & $38(52.1)$ & $35(79.5)$ & $8(47.1)$ & $15(88.2)$ & $6(46.2)$ & $5(50)$ & $8(80)$ & $3(50)$ \\
\hline \multirow{2}{*}{ PIT } & $\mathrm{S}$ & $66(90.4)$ & $40(90.9)$ & $14(82.4)$ & $12(70.6)$ & $13(100)$ & $7(70)$ & $9(90)$ & $4(66.7)$ \\
\hline & $\mathrm{R}$ & $7(9.6)$ & $4(9.1)$ & $3(17.6)$ & $5(29.4)$ & $0(0)$ & $3(30)$ & $1(10)$ & $2(33.3)$ \\
\hline \multirow{2}{*}{ IMP } & $\mathrm{S}$ & $71(97.3)$ & $42(95.5)$ & 15 (88.2) & $17(100)$ & $13(100)$ & $8(80)$ & $10(100)$ & $4(66.7)$ \\
\hline & $\mathrm{R}$ & $2(2.7)$ & $2(4.5)$ & $2(11.8)$ & $0(0)$ & $0(0)$ & $2(20)$ & $0(0)$ & $2(33.3)$ \\
\hline \multirow{2}{*}{ CL } & $S$ & $19(26)$ & $6(13.6)$ & $11(64.7)$ & $0(0)$ & $8(61.5)$ & $0(0)$ & $8(80)$ & $4(66.7)$ \\
\hline & $\mathrm{R}$ & $54(74)$ & $38(86.4)$ & $6(35.3)$ & $17(100)$ & $5(38.5)$ & $10(100)$ & $2(20)$ & $2(33.3)$ \\
\hline \multirow{2}{*}{ TGE } & $\mathrm{S}$ & $10(13.7)$ & $9(20.5)$ & $2(11.8)$ & $1(5.9)$ & $11(84.6)$ & $6(60)$ & $7(70)$ & $2(33.3)$ \\
\hline & $\mathrm{R}$ & $63(86.3)$ & $35(79.5)$ & $15(88.2)$ & $16(94.1)$ & $2(15.4)$ & $4(40)$ & $3(30)$ & $4(66.7)$ \\
\hline \multirow{2}{*}{ AT } & $\mathrm{S}$ & $40(54.8)$ & $10(22.7)$ & $7(41.2)$ & $0(0)$ & $12(92.3)$ & $1(10)$ & $6(60)$ & $1(16.70$ \\
\hline & $\mathrm{R}$ & $33(45.2)$ & $34(77.3)$ & $10(58.8)$ & $17(100)$ & $1(7.7)$ & $9(90)$ & $4(40)$ & $5(83.3)$ \\
\hline
\end{tabular}

Where, n- number, AMX -Amoxicillin, AMC- Amoxicillin + Clavulanic Acid, CN- Cephalexin, CTR- Ceftriaxone, CTX- Cefotaxime, CEC-Cefotaxime + Clavulanate, CAZ- Ceftazidime, CAC- Ceftazidime + Clavulanate, CPZ- Cefoperazone, CPM- Cefepime, PITPiperacillin + Tazobactum, IMP- Imipenem, GEN- Gentamycin, CIP- Ciprofloxacin, COT- Cotrimoxazole, CL- Colistin, TGETigecyclin, AT- Aztreonam, S- sensitive, R- resistant.

All the gram-negative organisms except Enterobacter showed $>70 \%$ sensitivity towards PIT. Pseudomonas aeruginosa, Proteus and Citrobacter were $100 \%$ sensitive to IMP. All the eight gram-negative organisms showed $>80 \%$ resistance against amoxicillin. Around six organisms (all except Proteus and Enterobacter) showed resistance towards AMC and five out of eight organisms showed resistance against CPM (all gram negatives except E. Coli, Proteus and Acinetobacter) and CAZ (all except E. Coli, Pseudomonas aeruginosa and Citrobacter). E. Coli was $>70 \%$ resistant towards AMX, AMC, CN, CTX, CIP and COT. The third most common organisms in our study Klebsiella and Pseudomonas aeruginosa were $>70 \%$ resistant to AMX, AMC, CN, CPM, CIP and TGE (Table 2).

\section{DISCUSSION}

This study was undertaken to study about the pattern of antibiotic administration in prophylaxis and treatment of surgical site infection along with extent to which the organisms exhibit resistance towards various classes of antibiotics in order to provide our treating clinicians with valuable information which could help them deliver appropriate antibiotic treatment to their patients.

\section{Demographic and clinical details}

In our study, the total sample size was 263 , out of which around $42.2 \%$ of the patients were belonging to the age group of 41-60 years which was found to be the most common age group in our study which was different from another study where 26-45 years was the most common age group and in another study where it was 21-40 years. ${ }^{9,10}$ This is probably because this age group is associated with more co-morbidities thus leading to increased incidence of SSIs. In our study, there were
$58.17 \%$ of males when compared to $41.82 \%$ females which was like other studies. ${ }^{9-11}$

The most common diagnosis found in our study was one of the emergency conditions, intestinal perforation (14.4\%). This could be probably because the prevalence of peptic ulcer disease (PUD) and its complications like duodenal perforation, pyloric perforation and gastric perforation are increasing nowadays. In our study, open abdomino-perineal resection $(22.1 \%)$ was the most common surgery done correlating with the most common diagnosis reported previously.

\section{Organisms associated with SSIs}

In our study, the culture report of pus samples says that around $92 \%$ of the total 263 samples were culture positive means that $92 \%$ study subjects had proven SSI which was different from a study done by Mengesha et al where $96(75 \%)$ out of the 128 wound swabs taken, were culture positive aerobically but was similar to a study done by Mama et al (91.6\%). ${ }^{11,12}$

The most common organism causing SSI in our study was E. Coli-ESBL which was similar to a study done by Jakribettu et al and Amare et al $(E$. Coli=24.3\%) but was different from other studies done by Mama et al, Akinkunmi et al and Sawdekar et al where Staphylococcus aureus was found to be the most common organism causing SSI. ${ }^{9,12-15}$ This may be probably due to poor hygienic practices followed by the patients. In a study done by Shaikh et al, it is said that exposure to various beta-lactum antibiotics causes mutation in the bacterial beta-lactamase genes, making them more resistant by producing extended spectrum betalactamase. ${ }^{16}$ In our study, the second most common 
causative organisms for SSI were MRSA and E. Coli (non-ESBL) as shown in some studies. ${ }^{17,18}$

\section{Antibiotic susceptibility pattern}

Our study results of antibiotic susceptibility of gram positive organisms showed that MRSA and MRCoNs were $100 \%$ resistant to penicillin and all the gram positive cocci were $100 \%$ sensitive to vancomycin and linezolid which was similar to a study done by Pal et al, Akinkunmi et al and Mengesha et al where the gram positive cocci showed $100 \%$ sensitivity towards vancomycin. ${ }^{11,15,19}$ MRSA showed $>50 \%$ resistance towards cotrimoxazole, erythromycin, clindamycin, cefoxitin and ciprofloxacin which was like a study done by Green et al and Kahsay et al. ${ }^{18,20}$ This shows that there is zero prevalence of VRSA (vancomycin resistant Staphylococcus aureus) in our hospital which is a welcoming fact.

MRCoNs showed $\geq 50 \%$ resistance towards cefoxitin, cefaclor, erythromycin, ciprofloxacin and cotrimoxazole as shown in studies done by Raza et al and Bhatt et al. 21,22 Staphylococcus aureus was $>50 \%$ resistant against gentamycin, erythromycin, clindamycin, ciprofloxacin and cotrimoxazole. This result shows that the grampositive organisms are becoming less sensitive to most prescribed antibiotics which could lead to extensive use of our precious broad-spectrum antibiotics like vancomycin, teicoplanin and linezolid for the treatment of simple infections. This warns us against the potential upcoming development of resistance against these broadspectrum antibiotics among micro-organisms.

The antibiotic susceptibility pattern of gram-negative organisms shows that all the gram- negative organisms except Enterobacter showed $>70 \%$ sensitivity towards piperacillin-tazobactum (PIT) which contrasts with a study where the gram-negative organisms show only $<50 \%$ sensitivity towards PIT. ${ }^{23}$ Pseudomonas aeruginosa, Proteus and Citrobacter were $100 \%$ sensitive to imipenem (IMP). All the eight gram-negative organisms showed $>80 \%$ resistance against amoxicillin. Around six organisms (all except Proteus and Enterobacter) showed resistance to amoxicillinclavulanic acid (AMC) and five out of eight organisms showed resistance against cefepime (CPM) (all gram negatives except E. Coli, Proteus and Acinetobacter) and ceftazidime (CAZ) (all except E. Coli, Pseudomonas aeruginosa and Citrobacter). E. Coli was $>70 \%$ resistant towards amoxicillin (AMX), amoxicillin-clavulanate (AMC), Cephalexin (CN), cefotaxime (CTX), ciprofloxacin (CIP) and cotrimoxazole (COT).

This was comparable to a study where E. Coli was, (100\%), (96.3\%), (92.6\%), (88.9\%), (77.8\%), (70.4\%), $(70.4 \%),(59.2 \%),(55.6 \%)$, and $(29.6 \%)$ resistant to amoxicillin, ampicillin, chloramphenicol, trimethoprimsulfamethoxazole, tetracycline, kanamycin, amikacin, gentamicin, ceftriaxone, and ciprofloxacin, respectively. ${ }^{14}$
Our results were comparable to another study where drug resistance of isolated gram-negative bacteria, irrespective of species/genus, was $92.3 \%$ to ampicillin, $92.3 \%$ to tetracycline and $92.3 \%$ to amoxicillin, $81.5 \%$ to ceftriaxone, $69.2 \%$ to amoxicillin clavulanic acid, $46.2 \%$ to ciprofloxacin, $26.2 \%$ to erythromycin and $16.9 \%$ to gentamicin. ${ }^{11}$ This high resistance of organisms to $\beta$ lactam is not surprising, as these antibiotics are the most used ones and resistant pattern were reported from many studies.

The third most common organisms in our study Klebsiella and Pseudomonas aeruginosa are $>70 \%$ resistant to AMX, AMC, CN, CPM, CIP and Tigecyclin (TGE). This result was like other studies done by Dessie et al, Snigdha et al and Patil et al. ${ }^{24-26}$ The lesser sensitivity gram negative organisms towards broader spectrum antibiotics like PIT and imipenem (IMP) show that the situation is unfavourable and alarming. This could be probably due to high preference for these antibiotics in treatment of SSIs despite the susceptibility of the gram-negative organisms towards narrow spectrum antibiotics.

\section{CONCLUSION}

We conclude that there is an urgent need for change in the prophylactic measures of surgical site infection which could effectively control the organisms causing SSI. This can be achieved by forming a protocol by the hospital committee, according to the local bacteriological profile and its antibiotic susceptibility pattern of organisms causing SSI.

\section{ACKNOWLEDGEMENTS}

I thank Dr B. M. Parashivamurthy, Professor and Head, Department of Pharmacology, MMC and RI, Mysore for his support and encouragement to carry-out this study. Also, I wish to thank the Professor and Head, Department of Surgery, KR hospital, Mysore, for their support. I would also like to thank all the staff members in the general surgery ward for their guidance.

\section{Funding: No funding sources}

Conflict of interest: None declared

Ethical approval: The study was approved by the Institutional Ethics Committee

\section{REFERENCES}

1. Mujagic E, Zwimpfer T, Marti WR, Zwahlen M, Hoffmann H, Kindler C, et al. Evaluating the optimal timing of surgical antimicrobial prophylaxis: study protocol for a randomized controlled trial. Trials. 2014;15(188):1-11.

2. Prajapati V, Bhatt JD. Evaluation of rational usage of antimicrobial agents in the medicine department at tertiary teaching care hospital, Gujarat. Int J Pharm Sci Res. 2014;5(3):865-73. 
3. George SS, Varghese SR, Samuel CJ. Evaluation of antibiotic prescribing patterns among medical practitioners in North India. Int J App Basic Med Res. 2013;2(8):952-7.

4. Odonkor ST, Addo KK. Bacteria resistance to antibiotics: recent trends and challenges. Int $\mathrm{J}$ Biol Med Res. 2011;2(4):1204-10.

5. Salkind AR, Rao KC. Antibiotic prophylaxis to prevent surgical site infections. Am Fam Physician. 2011;83(5):585-90.

6. Balouiri M, Sadiki M, Ibnsouda SK. Methods for in vitro evaluating antimicrobial activity: A review. J Pharm Analysis. 2016;6(2):71-9.

7. Akhi MT, Ghotaslou R, Beheshtirouy S, Asgharzadeh M, Pirzadeh T, Asghari B, Alizadeh N, Ostadgavahi AT, Somesaraei VS, Memar MY. Antibiotic susceptibility pattern of aerobic and anaerobic bacteria isolated from surgical site infection of hospitalized patients. Jundishapur $\mathbf{J}$ Microbiol. 2015;8(7).

8. Hubab M. Antibiotic susceptibility profile of bacterial isolates from post-surgical wounds of patients in tertiary care hospitals of Peshawar, Pakistan. J Pak Med Assoc. 2019;69(3):448.

9. Sawdekar H, Sawdekar R, Wasnik VR. Antimicrobial susceptibility pattern of bacterial isolates from wound infection and their sensitivity to antibiotic agents at super specialty hospital, Amravati city, India. Int J Res Med Sci. 2015;3(2):433-9.

10. Adegoke AA, Mvuyo T, Anthony O, Steve J. Studies on multiple antibiotic resistant bacterial isolated from surgical site infection. Scient Res Essays. 2010;5(24):3876-81.

11. Mengesha RE, Kasa BGS, Saravanan M, Berhe DF, Wasihun AG. Aerobic bacteria in post-surgical wound infections and pattern of their antimicrobial susceptibility in Ayder Teaching and Referral Hospital, Mekelle, Ethiopia. BMC Res Notes. 20147:575.

12. Reichman DE, Greenberg JA. Reducing surgical site infections: a review. Rev Obstet Gynecol. 2009;2(4):212-21.

13. Madhusudan E, Jakribettu RP, Boloor R, Rao SN. Study of pre-surgical antimicrobial prescribing pattern and correlation with microbiological data in a tertiary care hospital. EC Microbiol. 2015;2(4):36573.

14. Amare B, Abdurrahman Z, Moges B, Ali J, Muluken L. Postoperative surgical site bacterial infections and drug susceptibility patterns at Gondar University Teaching Hospital, Northwest Ethiopia. J Bacteriol Parasitol. 2011;2:126.

15. Akinkunmi EO, Adesunkanmi AR, Lamikanra A. Pattern of pathogens from surgical wound infections in a Nigerian hospital and their antimicrobial susceptibility profiles. Afr Health Sci. 2014;14(4):802-9.
16. Shaikh S, Fatima J, Shakil S, Rizvi SMD, Kamal MA. Antibiotic resistance and extended spectrum beta-lactamases: Types, epidemiology and treatment. Saudi J Biol Sci. 2015;22(1):90-101.

17. Kahsay A, Mihret A, Abebe $\mathrm{T}$, Andualem $\mathrm{T}$. Isolation and antimicrobial susceptibility pattern of Staphylococcus aureus in patients with surgical site infection at Debre Markos Referral Hospital, Amhara Region, Ethiopia. Arch Public Health. 2014;72(1):16.

18. Mama M, Abdissa A, Sewunet T. Antimicrobial susceptibility pattern of bacterial isolates from wound infection and their sensitivity to alternative topical agents at Jimma University Specialized Hospital, South-West Ethiopia. Ann Clin Microbiol Antimicrob. 2014;13(14):1-10.

19. Pal N, Guhathakurtha R. Surgical site infection in surgery ward at a tertiary care hospital: the infection rate and the bacteriological profile. IOSR J Pharm. 2012;2(5):1-5.

20. Green BN, Johnson CD, Egan JT, Rosenthal M, Griffith EA, Evans MW. Methicillin-resistant Staphylococcus aureus: an overview for manual therapists. J Chiropract Med. 2012;11(1):64-76.

21. Raza MS, Chander A, Ranabhat A. Antimicrobial susceptibility patterns of the bacterial isolates in postoperative wound infections in a tertiary care hospital, Kathmandu, Nepal. Open J Med Microbiol. 2013;3(3):159-63.

22. Bhatt CP, Baidya R, Karki P, Shah RK, Miya R, Mahashate $\mathrm{P}$, et al. Multi drug resistance bacterial isolates of surgical site infection. Open $\mathrm{J}$ Med Microbiol. 2014;4:203-9.

23. Akhi MT, Ghotaslou R, Beheshtirouy S, Asgharzadeh M, Pirzadeh T, Asghari B, et al. Antibiotic susceptibility pattern of aerobic and anaerobic bacteria isolated from surgical site infection of hospitalized patients. Jundishapur $\mathbf{J}$ Microbiol. 2015;8(7):e20309.

24. Dessie W, Mulugeta G, Fentaw S, Mihret A, Hassen M, Abebe E. Pattern of bacterial pathogens and their susceptibility isolated from surgical site infections at selected referral hospitals, Addis Ababa, Ethiopia. Int J Microbiol. 2016;2016:1-8.

25. Asok PNS, Lal S, San S, Fousiya KS, Sreeja PA. Infectious wounds: assessing risk factors, severity and anti-microbial sensitivity patterns. World $\mathbf{J}$ Pharm Pharm Sci 2016;5(7):1298-316.

26. Patil SB, Paramne A, Harsh S. antibiotic susceptibility of wound isolates in plastic surgery patients at a tertiary care centre. Indian J Plast Surg. 2016;49(2):198-205.

Cite this article as: Lakshmi SK, Gowda HN, Anuradha K. Antibiotic susceptibility pattern of organisms causing surgical site infection. Int J Basic Clin Pharmacol 2020;9:1405-11. 